\title{
Prediction of Phase Behavior for the System Methane-Carbon Dioxide- Hydrogen Sulfide-Water with the PR and PC-SAFT Equations of State
}

\author{
Germán A. Ávila-Méndez ${ }^{1}$, Daimler N. Justo-García ${ }^{1}$, Fernando García-Sánchez ${ }^{2, *}$ and \\ Blanca E. García-Flores ${ }^{2}$
}

\author{
${ }^{I}$ Departamento de Ingeniería Química Petrolera, ESIQIE, Instituto Politécnico Nacional, Unidad Profesional Adolfo \\ López Mateos, 07738 México, D.F., México \\ ${ }^{2}$ Laboratorio de Termodinámica, Programa de Investigación en Ingeniería Molecular, Instituto Mexicano del Petróleo. \\ Eje Central Lázaro Cárdenas 152, 07730 México, D.F., México
}

\begin{abstract}
In this work, we present the predicted multiphase behavior (vapor-liquid, liquid-liquid, and vapor-liquid-liquid equilibria) for a quaternary mixture containing methane, carbon dioxide, hydrogen sulfide, and water. The capabilities of the PR (Peng-Robinson) and PC-SAFT (Perturbed-Chain Statistical Associating Fluid Theory) equations of state (EoS) to predict the phase behavior exhibited by this mixture were compared and analyzed. The computer algorithm used for isothermal multiphase flash calculations is based on the minimization of the Gibbs energy along with stability analysis to find the most stable state of the system. The binary interaction parameters used with the PR EoS for modeling this system were taken from the literature whereas the interaction parameters for the PC-SAFT were obtained from the regression of binary vapor-liquid equilibrium data. The results obtained differ from each other and demonstrate different capabilities and accuracies of the present thermodynamic models in the predictions.
\end{abstract}

Keywords: Equation of state, Gibbs energy, PC-SAFT, Phase behavior, Stability analysis, Vapor-Liquid equilibrium, LiquidLiquid equilibrium, Vapor-Liquid-Liquid equilibrium.

\section{INTRODUCTION}

The complex task to represent the phase behavior of water is well-known; this is mainly attributed to the unique characteristics of water such as polarity and/or association, thus making difficult to estimate the phase behavior if the water is mixed with some other components with similar properties, like polar components such as carbon dioxide or hydrogen bonding in the case of hydrogen sulfide. These mixtures are important in the oil extraction industry because nowadays many reservoirs report the extraction of oil + water + non-hydrocarbon gases mixtures, and it is very important for this industry to count with feasible tools used in commercial simulators, like thermodynamic models, to perform the extraction simulations and reconfigurations of the facilities inside the refineries with high accuracy.

The aim of this work is to test the capabilities of the PR [1] and PC-SAFT [2] EoS using only one binary interaction parameter for each model and a reliable technique for multiphase flash calculations for predicting the multiphase behavior (vapor-liquid, liquid-liquid, and vapor-liquidliquid) exhibited experimentally by the quaternary system methane-carbon dioxide-hydrogen sulfide-water [3] over

*Address correspondence to this author at the Laboratorio de Termodinámica, Programa de Investigación en Ingeniería Molecular, Instituto Mexicano del Petróleo. Eje Central Lázaro Cárdenas 152, 07730 México, D.F., México; Tel: +52 559175 6574; Fax: +52 559175 6380;

E-mail: fgarcias@imp.mx specific temperature and pressure ranges. Here, it is worth mentioning that although there are other equations of state published in the literature, the main reason to select the PR and the PC-SAFT EoS in an attempt to compare their performance in this work is that these equations are very widely used for phase equilibrium calculations of fluid mixtures, including those mixtures encountered in the natural-gas and petroleum industries, and because presently most of the commercially available process simulators include these EoS in their models bank. The reader is referred to the original articles published by Peng and Robinson [1] and by Gross and Sadowski [2] for a detailed description of these equations of state. A description of the associating term used in the PC-SAFT EoS can be found elsewhere [4-6]

\section{SOLUTION PROCEDURE}

The solution procedure uses an efficient computational procedure for solving the isothermal multiphase problem by assuming that the system is initially monophasic. A stability test allows verifying whether the system is stable or not. In the latter case, it provides an estimation of the composition of an additional phase; the number of phases is then increased by one and equilibrium is achieved by minimizing the Gibbs energy. This approach, considered as a stage wise procedure [7, 8], is continuously applied until a stable solution is found. 
In this technique, the stability analysis of a homogeneous system of composition $\mathbf{z}$, which is based on the minimization of the distance separating the Gibbs energy surface from the tangent plane at $\mathbf{z}$, is considered $[9,10]$. In terms of fugacity coefficients, $\varphi_{i}$, this criterion for stability can be written as [10]

$$
F(\xi)=1+\sum_{i=1}^{N} \xi_{i}\left[\ln \xi_{i}+\ln \phi_{i}(\xi)-h_{i}-1\right] \geq 0 \quad \forall \xi>0
$$

where $\xi_{i}$ are mole numbers with corresponding mole fractions as $y_{i}=\xi_{i} / \sum_{j=1}^{N} \xi_{j}$, and

$h_{i}=\ln z_{i}+\ln \phi_{i}(\mathbf{z}) \quad i=1, \ldots, N$

Equation (1) requires that the tangent plane at no point lies above the Gibbs energy surface and this is achieved when $F(\xi)$ is positive in all of its minima. Consequently, a minimum of $F(\xi)$ should be considered in the interior of the permissible region $\sum_{i=1}^{N} y_{i}=1, \forall \mathbf{y} \geq 0$. Since to test condition 1 for all trial compositions is not physically possible, then it is sufficient to test the stability at all stationary points of $F(\xi)$ since this function is not negative at all stationary points. Here, the quasi-Newton BFGS minimization method [11] was applied to equation (1) for determining the stability of a given system of composition $\mathbf{z}$ at specified temperature and pressure.

Once instability is detected with the solution at $p-1$ phases, the equilibrium calculation is solved by minimization of the following function

$$
\operatorname{Min}_{n_{i}^{(\phi)}} \Delta g=\sum_{\phi=1}^{p} \sum_{i=1}^{N} n_{i}^{(\phi)} \ln \left(\frac{x_{i}^{(\phi)} \varphi_{i}^{(\phi)} P}{P^{\circ}}\right)
$$

subject to the inequality constraints given by

$$
\sum_{\phi=1}^{p-1} n_{i}^{(\phi)} \leq z_{i} \quad i=1, \ldots, N
$$

and

$n_{i}^{(\phi)} \geq 0 \quad i=1, \ldots, N ; \varphi=1, \ldots, p-1$

where $z_{i}$ is the mole fraction of the component $i$ in the system, $n_{i}^{(\phi)}(i=1, \ldots, N ; \varphi=1, \ldots, p-1)$ is the mole number of component $i$ in phase $\varphi$ per mole of feed, $x_{i}^{(\phi)}$ is the mole fraction of component $i$ in phase $\varphi, T$ is the temperature, $P$ is the pressure, and $P^{\circ}$ is the pressure at the standard state of $1 \mathrm{~atm}(101.325 \mathrm{kPa})$. In equation (3) the variables $n_{i}^{(p)}, x_{i}^{(p)}$, and $\varphi_{i}^{(p)}$ are considered functions of $n_{i}^{(\phi)}$.

Equation (3) was solved using an unconstrained minimization algorithm by keeping the variables $n_{i}^{(\phi)}$ inside the convex constraint domain given by equations (4) and (5) during the search for the solution. In this case, we used a hybrid approach to minimize equation (3) starting with the steepest-descent method in conjunction with a robust initialization supplied from the stability test to ensure a certain progress from initializations, and ending with the quasi-Newton BFGS method which ensures the property of strict descent of the Gibbs energy surface. A detailed description of this approach for solving the isothermal multiphase problem can be found elsewhere [12]

\section{RESULTS AND DISCUSSSION}

The problem to determine the phase behavior developed by mixtures containing great amount of water within an interval of pressures and temperatures is due to the complex characteristics of water and, in most cases, the large differences between the critical temperatures of the components that are mixed with water. In this case, a quaternary mixture made up of methane $\left(\mathrm{CH}_{4}\right)$, carbon dioxide $\left(\mathrm{CO}_{2}\right)$, hydrogen sulfide $\left(\mathrm{H}_{2} \mathrm{~S}\right)$, and water $\left(\mathrm{H}_{2} \mathrm{O}\right)$ was studied. The nominal composition in mole fraction for this mixture (so-called Mixture 2 by Huang et al. [3]) is: 0.05 $\mathrm{CH}_{4}, 0.05 \mathrm{CO}_{2}, 0.40 \mathrm{H}_{2} \mathrm{~S}$, and $0.50 \mathrm{H}_{2} \mathrm{O}$. Here, it should be mentioned that water has a variety of intrinsic characteristics such as polarity and association contribution, carbon dioxide has quadrupolar properties, and hydrogen sulfide could be considered as associated and with certain degree of polarity. When all these components are mixed there is no way to give a precise explanation of the complex phase behavior of the mixture from the pure component characteristics. Once components are mixed the only way to try to give an explanation of the phase behavior is through the use of thermodynamic models that take into account the variety of the different contributions due to each one of the characteristics of the pure components that are involved.

This mixture was also studied by Nutakki et al. [13] some years ago and more recently by $\mathrm{Li}$ and Firoozabadi [14]. In the former work, the multiphase equilibrium calculations for binary, ternary, and quaternary hydrocarbonwater systems at high temperature were performed using the Schmidt-Wenzel EoS [15]. The solubility of water in the hydrocarbon-rich liquid phase and vapor phases was modeled using a constant binary interaction parameter between water and hydrocarbon, while the solubility of hydrocarbons in the aqueous phase was calculated using a temperature-dependent binary interaction parameter. Twoand three-phase equilibrium calculations were performed using the method of successive substitution. A stability analysis using the tangent plane criterion was used to determine the correct number of phases present.

At high temperatures the solubility of water in the hydrocarbon-rich liquid phase was calculated satisfactorily both for mixtures of water and pure hydrocarbon components, and for mixtures of water and petroleum fractions. The binary interaction parameters used in the hydrocarbon-rich liquid phase and the vapor phase were found to be dependent on the type of hydrocarbon. 
The solubility of hydrocarbons in the aqueous phase was calculated reasonably well using temperature-dependent interaction coefficients in the aqueous phase. Nutakki et al. found that above $370 \mathrm{~K}$, the binary interaction parameters in the aqueous phase were linear functions of temperature. Binary interaction parameters from two phase binary data were found to be satisfactory to calculate three phase multicomponent equilibrium.

In the latter work, $\mathrm{Li}$ and Firoozabadi calculated the multiphase equilibrium for binary, ternary, and quaternary hydrocarbon-water systems using a modified version of the cubic plus association (CPA) EoS [16] by applying the "pseudo-association" concept to explicitly consider the cross association between water and non-water compounds. In this approach, each pseudo-association (i.e., $\mathrm{CH}_{4}, \mathrm{CO}_{2}$, and $\mathrm{H}_{2} \mathrm{~S}$ ) were assumed to possess four association sites, similar to water molecules. In addition, it is assumed that there is neither cross association nor self association between pseudo-associating components, and that the cross association is symmetric between two sites of different types of water and pseudo-associating component. They illustrated the performance of their approach by comparison with the experiments for the phase compositions of $\mathrm{H}_{2} \mathrm{O}-\mathrm{CH}_{4}, \mathrm{H}_{2} \mathrm{O}$ $\mathrm{C}_{2} \mathrm{H}_{6}, \mathrm{H}_{2} \mathrm{O}-\mathrm{CO}_{2}$, and $\mathrm{H}_{2} \mathrm{O}-\mathrm{H}_{2} \mathrm{~S}$, among other binary mixtures, and the $\mathrm{H}_{2} \mathrm{O}-\mathrm{CH}_{4}-\mathrm{CO}_{2}-\mathrm{H}_{2} \mathrm{~S}$ quaternary mixture, in two and three phases. The results presented by these authors showed that the modified approach enhanced the accuracy in phase behavior calculations for the mixtures studied.

Here, we have also used the nominal composition for mixture 2 reported by Huang et al. [3] to test the robustness, efficiency and reliability of the computational technique employed in this work, and to compare the PC-SAFT and PR EoS modeling results. No modification to these equations was attempted to enhance their accuracy in phase behavior calculations, therefore these equations of state were used in their original form. Experimental two- and threephase equilibrium data were compared with values calculated from both equations of state.

The pure-component physical properties (i.e., critical temperature $T_{c}$, critical pressure $P_{c}$, and acentric factor $\omega$ ) of $\mathrm{CH}_{4}, \mathrm{CO}_{2}, \mathrm{H}_{2} \mathrm{~S}$, and $\mathrm{H}_{2} \mathrm{O}$ for the $\mathrm{PR}$ EoS were taken from Ambrose [17]. For the PC-SAFT EoS, the three purecomponent parameters (i.e., temperature independent segment diameter $\sigma$, depth of the potential $\varepsilon$, and number of segments per chain $m$ ) of the non-associating compounds, $\mathrm{CH}_{4}$ and $\mathrm{CO}_{2}$, were taken from Gross and Sadowski [2] whereas for the associating compounds, $\mathrm{H}_{2} \mathrm{~S}$ and $\mathrm{H}_{2} \mathrm{O}$, these three pure-component parameters plus the two additional association parameters (i.e., the association energy $\varepsilon^{A B}$ and volume $\kappa^{A B}$ for each site-site interaction) were taken from Tang and Gross [18].

Table 1 presents the physical properties of the four compounds forming the mixture studied as well as the values of the molecular parameters for the non-associating and associating compounds characterizing the PC-SAFT EoS. In this case, the associating compounds $\mathrm{H}_{2} \mathrm{~S}$ and $\mathrm{H}_{2} \mathrm{O}$ were considered to have two bonding sites.

The binary interaction parameters used in this work for the PR EoS were taken from the literature [19-21], and they are: $k_{\mathrm{C}_{1}-\mathrm{CO}_{2}}=0.1300, k_{\mathrm{C}_{1}-\mathrm{H}_{2} \mathrm{~S}}=0.0933, k_{\mathrm{C}_{1}-\mathrm{H}_{2} \mathrm{O}}=0.5000$, $k_{\mathrm{CO}_{2}-\mathrm{H}_{2} \mathrm{~S}}=0.0974, k_{\mathrm{CO}_{2}-\mathrm{H}_{2} \mathrm{O}}=0.1896$, and $k_{\mathrm{H}_{2} \mathrm{~S}-\mathrm{H}_{2} \mathrm{O}}=0.0400$, while the interaction parameters for the PC-SAFT EoS were fitted from binary vapor-liquid equilibrium data by minimizing either the objective function $S_{1}$

$S_{1}=\sum_{i=1}^{M}\left[\left(\frac{P_{i}^{\text {exp }}-P_{i}^{\text {calc }}}{P_{i}^{\exp }}\right)^{2}+\left(y_{i}^{\text {exp }}-y_{i}^{\text {calc }}\right)^{2}\right]$

for the bubble-point pressure method, or the objective function $S_{2}$

$S_{2}=\sum_{i=1}^{M}\left[\left(x_{i}^{e x p}-x_{i}^{c a l c}\right)^{2}+\left(y_{i}^{e x p}-y_{i}^{c a l c}\right)^{2}\right]$

for the flash calculation method.

In these equations, $P_{i}^{\text {exp }}-P_{i}^{\text {calc }}, x_{i}^{\text {exp }}-x_{i}^{\text {calc }}$, and $y_{i}^{\text {exp }}-y_{i}^{\text {calc }}$ are the differences between the experimental and calculated values of, respectively, bubble-point pressures, liquid compositions, and vapor compositions for an experiment $i$, and $M$ is the number of experimental points. Equations (6) and (7) were minimized using the simplex optimization procedure of Nelder and Mead [22] with convergence accelerated by the Wegstein algorithm [23].

It is interesting to note that although the bubble-point pressure method is one of the most popular methods used for modeling vapor-liquid equilibrium data of binary systems through the minimization of the objective function $S_{1}$, it is

Table 1. Pure-component Physical Properties and Characteristic Parameters for the PR and PC-SAFT EoS

\begin{tabular}{|l|c|c|c|c|c|c|c|c|c|}
\hline Component $i$ & $M_{i}$ & $T_{c, i}$ & $P_{c, i}$ & $\omega_{i}$ & $m_{i}$ & $\sigma_{i}$ & $\varepsilon_{i} / k$ & $\kappa^{A_{i} B_{i}}$ & $\varepsilon^{A_{i} B_{i}} / k$ \\
\hline \hline & $(\mathrm{g} / \mathrm{mol})$ & $(\mathrm{K})$ & $(\mathrm{MPa})$ & & & $(\AA)$ & $(\mathrm{K})$ & $(\mathrm{K})$ \\
\hline $\mathrm{CH}_{4}$ & 16.04 & 190.58 & 4.604 & 0.012 & 1.0000 & 3.7039 & 150.03 & \\
\hline $\mathrm{CO}_{2}$ & 44.01 & 304.10 & 7.375 & 0.239 & 2.7290 & 2.7852 & 169.21 & \\
\hline $\mathrm{H}_{2} \mathrm{~S}$ & 34.08 & 373.20 & 8.940 & 0.109 & 1.6490 & 3.0550 & 229.84 & 0.001000 & 536.6 \\
\hline $\mathrm{H}_{2} \mathrm{O}$ & 18.02 & 647.14 & 22.050 & 0.328 & 1.0656 & 3.0007 & 366.51 & 0.034868 & 2500.7 \\
\hline
\end{tabular}


biased toward fitting liquid compositions. Consequently, the calculated phase envelopes may not necessarily close at the last experimental composition. On the contrary, when the flash method is used for fitting vapor-liquid equilibrium data, both the liquid and vapor compositions appear in the objective function $S_{2}$, and therefore treated equally. This allows analyzing the over prediction of the mixture critical points of the isotherms; i.e., the phase envelopes can be calculated to near critical conditions independent of the location of the last experimental composition measurements.

The optimized binary interaction parameters obtained for the PC-SAFT EoS using objective functions $S_{1}$ or

$S_{2} \quad$ are: $\quad k_{\mathrm{C}_{1}-\mathrm{CO}_{2}}=0.0497 \quad$ [24], $\quad k_{\mathrm{C}_{1}-\mathrm{H}_{2} S}=0.0582 \quad$ [25],

$k_{C_{1}-H_{2} O}=-5.33 \times 10^{-6}(T / \mathrm{K})^{2}+4.73 \times 10^{-3}(T / \mathrm{K})-0.947$ [26],

$k_{\mathrm{CO}_{2}-\mathrm{H}_{2} \mathrm{~S}}=0.0669 \quad[27], \quad k_{\mathrm{CO}_{2}-\mathrm{H}_{2} \mathrm{O}}=-0.0169 \quad$ [28], and

$k_{\mathrm{H}_{2} \mathrm{~S}-\mathrm{H}_{2} \mathrm{O}}=0.0362[29,30]$, where the numbers in brackets indicate the references from which the experimental VLE data were taken for the optimization of the interaction parameters.

Once the interaction parameters for the two equations of state were known, multiphase equilibrium calculations for the quaternary mixture at experimental conditions were performed. In addition, the two- and three-phase envelopes for this mixture were calculated using the PR and PC-SAFT EoS. This allows comparing the capability of both models to predict the experimental boundaries. It is important to mention that all predictions were carried out using only binary information from vapor-liquid equilibrium data and that the three phase envelope for mixture 2 was build by comparing only the pressure and temperature of transition between the two- and three-phases in equilibrium, since there is not experimental evidence about the compositions of each one of the components at these points. Fig. (1) shows the experimental and calculated two- and three-phase boundaries for this mixture. A more detailed discussion of the predicted phase behavior for this mixture with the PR and PC-SAFT models is given below.

\section{PR Equation of State Results}

The three-phase vapor-liquid-liquid equilibrium (VLLE) region calculated with the PR EoS and depicted in Fig. (1) for mixture 2 shows a fair agreement with the experimental three-phase dew point boundary and it is rather high with respect to the experimental three-phase bubble point boundary; both experimental curves reported by Huang et al. Overall, it can be said that the PR EoS gives a satisfactory qualitative representation of the three-phase phenomena, even better than that obtained with the PC-SAFT EoS, however, the PR EoS gives a poor description of the compositions at equilibrium inside the two- and three-phase region. This can be attributed to the lack of explicit contributions of the model; i.e., the polar behavior of carbon dioxide or the association and polar behavior of water were not taken into account in the PR equation. Nonetheless, even if these contributions could be included in the model in an explicit way, we did not do that because the purpose of this work was focused on the capability of this equation of state

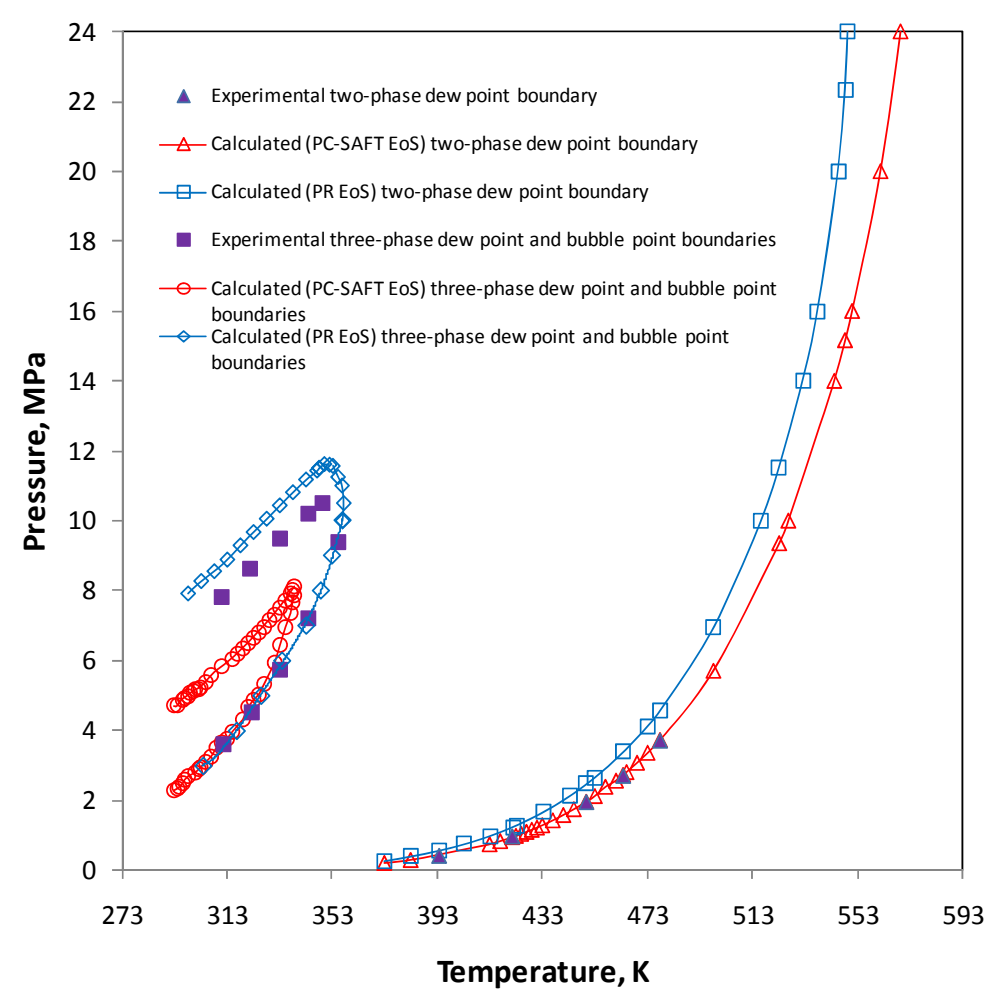

Fig. (1). Experimental and calculated phase boundaries for Mixture 2 (composition: $5 \mathrm{~mol} \% \mathrm{CH}_{4}, 5 \mathrm{~mol} \% \mathrm{CO}_{2}, 40 \mathrm{~mol} \% \mathrm{H}_{2} \mathrm{~S}$, and $50 \mathrm{~mol}$ $\left.\% \mathrm{H}_{2} \mathrm{O}\right)$. 
in its original form to represent the experimentally observed complex phase behavior developed by this mixture and compare its performance against another thermodynamic model. In this context, it should be mentioned that all phase equilibrium predictions with this equation were obtained using binary interaction parameters taken from the literature, which had previously been fitted from binary vapor-liquid equilibrium data, instead of using other interaction parameters fitted from three phase equilibrium data, as done, for instance, by Nutakki [31] to modeling the three-phase binary water-hydrocarbon systems data of Brady et al. [32] and Tsonopoulos and Wilson [33] with the Schmidt-Wenzel EoS in order to determine the interaction parameters between the hydrocarbon and water in the hydrocarbon liquid and aqueous phases. The latter is important because once the interaction parameters have been fitted at three phase equilibrium conditions, there is a risk to use them to predict the phase behavior of a given system at different conditions at which the interaction parameters were determined, so that the prediction may fail and/or give physical meaningless results. Fig. (1) also shows that the two-phase dew point boundary is over predicted by the PR EoS in comparison with the experimental data when temperature and pressure increase.

Table 2 presents the results of the predictions obtained with the PR EoS in both the aqueous vapor-liquid and the aqueous liquid-hydrogen sulfide dense fluid. The calculations were performed at two temperatures, one at $380.35 \mathrm{~K}$ and three pressures (7.56, 12.27, and 16.92 MPa), and the other one at $449.85 \mathrm{~K}$ and two pressures (11.00 and 18.17 MPa). This table shows that at temperatures higher at which the three phase region exists, the solubility of water in the vapor phase is over predicted by one or two orders of magnitude, whereas the solubility of methane in the aqueous phase is under predicted by, in most cases, one order of magnitude.

In the case of the aqueous liquid-hydrogen sulfide dense phase, the algorithm failed to converge with this equation of state at $310.95 \mathrm{~K}$ and pressures higher than $12 \mathrm{MPa}$. Therefore, no result is given in Table $\mathbf{2}$ for the two liquid-liquid equilibrium calculations performed at 13.00 and $16.46 \mathrm{MPa}$.

Regarding the three-phase VLLE calculations, Table $\mathbf{3}$ presents the predictions obtained with this equation of state at the two temperature and pressure conditions reported experimentally; i.e., $310.95 \mathrm{~K}$ and $6.26 \mathrm{MPa}$, and $338.75 \mathrm{~K}$ and 8.43 MPa. This table shows that, as expected, the solubility of water in the vapor- and hydrogen sulfide-rich liquid phase is over predicted by several orders of magnitude, especially in the hydrogen sulfide-rich liquid phase, while methane is under predicted in both liquid phases at the two temperature and pressure conditions. Of course, these results can be improved if different interaction parameters were used in the calculations such that proposed by Peng and Robinson [34] for modeling more accurately the phase compositions for binary systems of alkanes and water.

An inspection of the results listed in Table $\mathbf{3}$ indicates that the PR EoS could be able to represent the entire three phase region in the P-T diagram but it shows differences once the comparison against the experimental compositions are made. In this table, it can be seen that the largest differences are for the water composition in the aqueous phase and for the methane and carbon dioxide composition in the liquid rich hydrogen sulfide phase. These differences could not be attributed to the polarity of the components or to hydrogen bonding because methane, which does not have hydrogen bonding, shows noticeable differences in the liquid hydrogen sulfide-rich phase.

\section{PC-SAFT Equation of State Results}

The three-phase VLLE region calculated for mixture 2 with the PC-SAFT EoS is also shown in Fig. (1) on the pressure-temperature phase diagram. This figure reveals that there exists disagreement with the experimental VLLE region; i.e., the calculated three-phase VLLE region is smaller than the experimental one. Nevertheless, the calculated three-phase dew point boundary up to about 6 $\mathrm{MPa}$ is in good agreement with the experimental data reported by Huang et al., although it is not possible to compare the compositions obtained with the model against the experimental ones because this information is not available. As pressure increases, the differences between the experimental three-phase dew point boundary and the calculated with the model become larger. In the case of the three-phase bubble point boundary, it is rather low with respect to the experimental boundary. Nevertheless, despite the shortcoming of this model to properly predict the experimental three-phase VLLE region, this figure shows that the predicted three-phase region fell completely inside of the experimental one.

In order to give a quantitative comparison between the experimental compositions and those calculated with the model at two- and three phases at equilibrium, Tables 2 and 3 present the results obtained from multiphase equilibrium calculations. These tables also present the results reported by $\mathrm{Li}$ and Firoozabadi [14] for this mixture at the same conditions of temperature and pressure using their modified CPA model with cross association (ca). An examination of Table 2 shows that, in most cases, the calculated solubilities of water in the vapor phase and in the hydrogen sulfide-rich liquid phase are in very good agreement with the experimental data. Although these results are not, strictly speaking, comparable with those reported by $\mathrm{Li}$ and Firoozabadi, they reflect the effect of the association in this mixture, which is included in the PC-SAFT EoS. A possible better prediction of the component mole fractions in both phases could be obtained if the quadrupolar effect of the carbon dioxide was included in this model.

Table 3 presents the experimental and calculated VLLE mole fractions of components that form mixture 2 at two different temperatures and pressures. In this case, although the conditions of pressure at which the three phases were experimentally determined are above the three phase region calculated with the PC-SAFT EoS, we have included in this table the highest values of pressure that allowed us to predict 
Table 2. Vapor-liquid and Liquid-liquid Equilibria of Mixture 2

\begin{tabular}{|c|c|c|c|c|c|c|c|c|c|c|}
\hline \multirow[t]{2}{*}{$\mathbf{T}(\mathbf{K})$} & \multirow[t]{2}{*}{$\mathbf{P}(\mathbf{M P a})$} & \multirow[t]{2}{*}{ Comp. } & \multirow[b]{2}{*}{ Exp. } & \multirow[b]{2}{*}{$\mathbf{P R}(\mathbf{c a})^{a}$} & \multirow[b]{2}{*}{ PC-SAFT } & \multicolumn{5}{|c|}{ Composition (Mole Fraction) } \\
\hline & & & & & & $\mathbf{P R}$ & $\operatorname{Exp}$ & $\mathbf{P R}(\mathbf{c a})^{a}$ & PC-SAFT & PR \\
\hline \multicolumn{11}{|c|}{ Aqueous liquid-vapor } \\
\hline \multirow[t]{12}{*}{380.35} & \multirow[t]{4}{*}{7.56} & $\mathrm{CH}_{4}$ & $1.55 \times 10^{-4}$ & $1.60 \times 10^{-4}$ & $1.50 \times 10^{-4}$ & $5.68 \times 10^{-6}$ & 0.1182 & 0.0980 & 0.1008 & 0.0997 \\
\hline & & $\mathrm{CO}_{2}$ & $1.25 \times 10^{-3}$ & $1.43 \times 10^{-3}$ & $2.24 \times 10^{-3}$ & $2.87 \times 10^{-4}$ & 0.1112 & 0.0966 & 0.0987 & 0.0994 \\
\hline & & $\mathrm{H}_{2} \mathrm{~S}$ & 0.0304 & 0.0289 & 0.0308 & 0.0395 & 0.7485 & 0.7809 & 0.7764 & 0.7580 \\
\hline & & $\mathrm{H}_{2} \mathrm{O}$ & 0.9682 & 0.9695 & 0.9668 & 0.9602 & 0.0253 & 0.0244 & 0.0242 & 0.0429 \\
\hline & \multirow[t]{4}{*}{12.27} & $\mathrm{CH}_{4}$ & $3.32 \times 10^{-4}$ & $3.44 \times 10^{-4}$ & $3.20 \times 10^{-4}$ & $1.36 \times 10^{-5}$ & 0.1060 & 0.1008 & 0.1023 & 0.1005 \\
\hline & & $\mathrm{CO}_{2}$ & $2.26 \times 10^{-3}$ & $2.26 \times 10^{-3}$ & $3.61 \times 10^{-3}$ & $5.02 \times 10^{-4}$ & 0.1148 & 0.0984 & 0.0988 & 0.1000 \\
\hline & & $\mathrm{H}_{2} \mathrm{~S}$ & 0.0361 & 0.0372 & 0.0408 & 0.0516 & 0.7528 & 0.7778 & 0.7778 & 0.7519 \\
\hline & & $\mathrm{H}_{2} \mathrm{O}$ & 0.9613 & 0.9600 & 0.9553 & 0.9478 & 0.0264 & 0.0229 & 0.0212 & 0.0476 \\
\hline & \multirow[t]{4}{*}{16.92} & $\mathrm{CH}_{4}$ & $6.06 \times 10^{-4}$ & $5.78 \times 10^{-4}$ & $5.10 \times 10^{-4}$ & $2.39 \times 10^{-5}$ & 0.1207 & 0.1002 & 0.1020 & 0.0980 \\
\hline & & $\mathrm{CO}_{2}$ & $3.34 \times 10^{-3}$ & $2.81 \times 10^{-3}$ & $4.68 \times 10^{-3}$ & $6.54 \times 10^{-4}$ & 0.1176 & 0.0978 & 0.0976 & 0.0974 \\
\hline & & $\mathrm{H}_{2} \mathrm{~S}$ & 0.0392 & 0.0384 & 0.0429 & 0.0512 & 0.7322 & 0.7709 & 0.7749 & 0.7351 \\
\hline & & $\mathrm{H}_{2} \mathrm{O}$ & 0.9568 & 0.9582 & 0.9519 & 0.9482 & 0.0295 & 0.0311 & 0.0255 & 0.0695 \\
\hline \multirow[t]{8}{*}{449.85} & \multirow[t]{4}{*}{11.00} & $\mathrm{CH}_{4}$ & $3.50 \times 10^{-4}$ & $3.36 \times 10^{-4}$ & $7.80 \times 10^{-4}$ & $6.92 \times 10^{-5}$ & 0.1092 & 0.0905 & 0.0932 & 0.0874 \\
\hline & & $\mathrm{CO}_{2}$ & $1.64 \times 10^{-3}$ & $1.69 \times 10^{-3}$ & $2.76 \times 10^{-2}$ & $9.37 \times 10^{-4}$ & 0.1078 & 0.0892 & 0.0697 & 0.0868 \\
\hline & & $\mathrm{H}_{2} \mathrm{~S}$ & 0.0286 & 0.0341 & 0.0342 & 0.0598 & 0.6896 & 0.6979 & 0.7210 & 0.6551 \\
\hline & & $\mathrm{H}_{2} \mathrm{O}$ & 0.9694 & 0.9638 & 0.9375 & 0.9392 & 0.0938 & 0.1224 & 0.1162 & 0.1707 \\
\hline & \multirow[t]{4}{*}{18.17} & $\mathrm{CH}_{4}$ & $7.15 \times 10^{-4}$ & $7.16 \times 10^{-4}$ & $6.10 \times 10^{-4}$ & $2.01 \times 10^{-4}$ & 0.0928 & 0.0933 & 0.0942 & 0.0920 \\
\hline & & $\mathrm{CO}_{2}$ & $2.92 \times 10^{-3}$ & $2.95 \times 10^{-3}$ & $4.15 \times 10^{-3}$ & $1.20 \times 10^{-3}$ & 0.0914 & 0.0909 & 0.0911 & 0.0905 \\
\hline & & $\mathrm{H}_{2} \mathrm{~S}$ & 0.0517 & 0.0520 & 0.0469 & 0.0941 & 0.7040 & 0.7112 & 0.7162 & 0.6579 \\
\hline & & $\mathrm{H}_{2} \mathrm{O}$ & 0.9454 & 0.9433 & 0.9484 & 0.9037 & 0.1130 & 0.1035 & 0.0985 & 0.1597 \\
\hline \multicolumn{11}{|c|}{ Aqueous liquid-hydrogen sulfide dense fluid } \\
\hline \multirow[t]{8}{*}{310.95} & \multirow[t]{4}{*}{13.00} & $\mathrm{CH}_{4}$ & $8.59 \times 10^{-4}$ & $9.75 \times 10^{-4}$ & $8.60 \times 10^{-4}$ & n.c. & 0.0891 & 0.1013 & 0.1019 & n.c. \\
\hline & & $\mathrm{CO}_{2}$ & $3.62 \times 10^{-3}$ & $2.74 \times 10^{-3}$ & $5.05 \times 10^{-3}$ & n.c. & 0.0994 & 0.0991 & 0.0975 & n.c. \\
\hline & & $\mathrm{H}_{2} \mathrm{~S}$ & 0.0291 & 0.0303 & 0.0281 & n.c. & 0.8016 & 0.7882 & 0.7926 & n.c. \\
\hline & & $\mathrm{H}_{2} \mathrm{O}$ & 0.9666 & 0.9659 & 0.9660 & n.c. & $9.32 \times 10^{-3}$ & $1.14 \times 10^{-2}$ & $8.13 \times 10^{-3}$ & n.c. \\
\hline & \multirow[t]{4}{*}{16.46} & $\mathrm{CH}_{4}$ & $8.82 \times 10^{-4}$ & $1.04 \times 10^{-3}$ & $9.20 \times 10^{-4}$ & n.c. & 0.0891 & 0.1013 & 0.1018 & n.c. \\
\hline & & $\mathrm{CO}_{2}$ & $3.81 \times 10^{-3}$ & $2.83 \times 10^{-3}$ & $5.23 \times 10^{-3}$ & n.c. & 0.1061 & 0.0993 & 0.0973 & n.c. \\
\hline & & $\mathrm{H}_{2} \mathrm{~S}$ & 0.0281 & 0.0306 & 0.0285 & n.c. & 0.7958 & 0.7873 & 0.7923 & n.c. \\
\hline & & $\mathrm{H}_{2} \mathrm{O}$ & 0.9672 & 0.9655 & 0.9654 & n.c. & $9.05 \times 10^{-3}$ & $1.21 \times 10^{-2}$ & $8.58 \times 10^{-3}$ & n.c. \\
\hline
\end{tabular}

${ }^{a}$ Li and Firoozabadi [14] n.c.: Not converged.

the three phase VLLE at 310.95 and $338.75 \mathrm{~K}$. From Table 3, the calculated mole fractions at $310.95 \mathrm{~K}$ and $5.62 \mathrm{MPa}$, and at $338.75 \mathrm{~K}$ and $8.10 \mathrm{MPa}$, are close to the experimental values $(310.95 \mathrm{~K}$ and $6.26 \mathrm{MPa}$, and $338.75 \mathrm{~K}$ and 8.43 $\mathrm{MPa})$, and perhaps comparable with the results obtained by $\mathrm{Li}$ and Firoozabadi at the same conditions. This means that the PC-SAFT EoS could predict compositions at equilibrium very close to the experimental conditions of temperature and pressure if it was able to predict a wider three phase VLLE region. This is because the three-phase VLL pressures and the compositions of the phases are sensitive to the interaction parameters. 
Table 3. Vapor-liquid-liquid Equilibrium of Mixture 2

\begin{tabular}{|c|c|c|c|c|c|c|c|c|c|c|c|c|}
\hline \multicolumn{7}{|c|}{ Comp. } & \multicolumn{6}{|c|}{ Composition (mole fraction) } \\
\hline \multicolumn{5}{|c|}{$\mathrm{H}_{2} \mathrm{~S}$ Liquid Phase } & \multicolumn{4}{|c|}{ Aqueous Phase } & \multicolumn{4}{|c|}{ Vapor Phase } \\
\hline & Exp. & $\mathbf{P R}$ (ca) ${ }^{a}$ & PC-SAFT $^{b}$ & PR & Exp. & $\mathbf{P R}(\mathbf{c a})^{a}$ & PC-SAFT $^{b}$ & $\mathbf{P R}$ & Exp. & $\mathbf{P R}(\mathbf{c a})^{a}$ & PC-SAFT $^{b}$ & PR \\
\hline \multicolumn{13}{|c|}{$T / \mathrm{K}=310.95, P / \mathrm{MPa}=6.26$} \\
\hline $\mathrm{CH}_{4}$ & 0.0653 & 0.0616 & 0.0448 & 0.0350 & $4.90 \times 10^{-4}$ & $5.98 \times 10^{-4}$ & $4.10 \times 10^{-4}$ & $3.67 \times 10^{-7}$ & 0.3213 & 0.3596 & 0.2812 & 0.2829 \\
\hline $\mathrm{CO}_{2}$ & 0.1049 & 0.0971 & 0.0792 & 0.0763 & $3.50 \times 10^{-3}$ & $2.61 \times 10^{-3}$ & $4.26 \times 10^{-3}$ & $7.98 \times 10^{-5}$ & 0.1739 & 0.1219 & 0.1577 & 0.1622 \\
\hline $\mathrm{H}_{2} \mathrm{~S}$ & 0.8197 & 0.8292 & 0.8667 & 0.8484 & 0.0284 & 0.0310 & 0.0293 & 0.0147 & 0.5028 & 0.5169 & 0.5593 & 0.5515 \\
\hline $\mathrm{H}_{2} \mathrm{O}$ & 0.0101 & 0.0122 & 0.0093 & 0.0403 & 0.9677 & 0.9659 & 0.9660 & 0.9852 & $2.14 \times 10^{-3}$ & $1.63 \times 10^{-3}$ & $1.83 \times 10^{-3}$ & $3.35 \times 10^{-3}$ \\
\hline \multicolumn{13}{|c|}{$T / \mathrm{K}=338.75, P / \mathrm{MPa}=8.43$} \\
\hline $\mathrm{CH}_{4}$ & 0.0580 & 0.0641 & 0.0499 & 0.0396 & $3.85 \times 10^{-4}$ & $4.15 \times 10^{-4}$ & $3.30 \times 10^{-4}$ & $1.70 \times 10^{-6}$ & 0.1872 & 0.2057 & 0.1674 & 0.1857 \\
\hline $\mathrm{CO}_{2}$ & 0.0904 & 0.0922 & 0.0759 & 0.0729 & $2.72 \times 10^{-3}$ & $2.47 \times 10^{-3}$ & $3.88 \times 10^{-3}$ & $1.72 \times 10^{-4}$ & 0.1484 & 0.1185 & 0.1274 & 0.1363 \\
\hline $\mathrm{H}_{2} \mathrm{~S}$ & 0.8287 & 0.8264 & 0.8602 & 0.8315 & 0.0321 & 0.0326 & 0.0357 & 0.0253 & 0.6557 & 0.6704 & 0.6997 & 0.6670 \\
\hline $\mathrm{H}_{2} \mathrm{O}$ & 0.0212 & 0.0174 & 0.0140 & 0.0561 & 0.9684 & 0.9645 & 0.9602 & 0.9745 & $8.66 \times 10^{-3}$ & $5.44 \times 10^{-3}$ & $5.50 \times 10^{-3}$ & $1.09 \times 10^{-2}$ \\
\hline
\end{tabular}

${ }^{a} \mathrm{Li}$ and Firoozabadi [14].

${ }^{b}$ Calculations performed at $310.95 \mathrm{~K}$ and $5.62 \mathrm{MPa}$, and at 338.75 K and 8.10 MPa; above these pressures only LLE was found.

Fig. (1) also shows the experimental and predicted twophase dew point boundary for mixture 2 . This figure shows that there exists an excellent agreement between the calculated two-phase dew point boundary with the PC-SAFT $\mathrm{EoS}$ and the experimental data, and it follows a regular trend at higher pressures.

Finally, it would have been interesting to apply the socalled PPR78 (Predictive 1978, PR EoS) model [35] to predict the two- and three-phase equilibrium data of mixture 2. This model, based on the PR EoS as published by Robinson and Peng in 1978 [36], incorporates a group contribution method to estimate the interaction parameter $k_{i j}$, which makes it predictive. At present, the $\mathrm{CH}_{4}, \mathrm{H}_{2} \mathrm{~S}$, and $\mathrm{CO}_{2}$ groups have already been reported [35, 37, 38], but, unfortunately, the group for $\mathrm{H}_{2} \mathrm{O}$ is not yet available in the open literature. A feature of the PPR78 model is that the interaction parameter $k_{i j}$, which characterizes molecular interactions between molecules $i$ and $j$, is dependent on temperature, so that the model can be applied over a wide range of temperature. As a consequence, this model is able to predict phase equilibria for mixtures containing hydrocarbon and non-hydrocarbon $\left(\mathrm{CO}_{2}, \mathrm{~N}_{2}\right.$, and $\left.\mathrm{H}_{2} \mathrm{~S}\right)$ components with high accuracy over wide temperature and pressure ranges.

\section{CONCLUSIONS}

The capabilities of two thermodynamic models, the PCSAFT and PR EoS, to predict the multiphase behavior experimentally exhibited by the quaternary mixture made up methane, carbon dioxide, hydrogen sulfide, and water, for a given composition and over specific temperature and pressure conditions, were investigated. The phase equilibrium calculations were carried out using an efficient computational numerical procedure based on the system Gibbs energy along with thermodynamic stability tests to find the most stable state of the system. This procedure (isothermal multiphase flash) was used to predict two- and three-phase envelopes.

The results obtained showed that both thermodynamic models present weakness in their phase equilibrium predictions. The PC-SAFT EOS gave a better prediction in composition of the two- and three-phase in equilibrium at the experimental conditions, although the calculated threephase VLLE region was smaller and displaced from that one experimentally observed. On the contrary, the PR EoS gave a better agreement with the three-phase VLLE experimentally observed, but the prediction of the compositions of the phases in equilibrium was, as expected, rather poor.

Overall, both models were capable to give a reasonable description of the multiphase behavior of the mixture studied using only binary information from two phase liquid-vapor equilibrium data. This is due mainly to that the three-phase VLL pressures and the compositions of the phases are very sensitive to the interaction parameters, which could be improved if these parameters are adjusted from experimental two- and three-phase equilibrium data for water-hydrocarbon, carbon dioxide-hydrocarbon, and hydrogen sulfide-hydrocarbon binary systems.

\section{CONFLICT OF INTEREST}

\section{None Declared}

\section{ACKNOWLEDGEMENTS}

This work was supported by the Mexican Petroleum Institute under Research Project D.00406. Two of the authors (G. A. A.-M. and D. N. J.-G.) gratefully acknowledge 
the National Polytechnic Institute for their financial support through the Project SIP-20110150.

\section{REFERENCES}

[1] D.-Y. Peng and D. B. Robinson, "A new two-constant equation of state”, Ind. Eng. Chem. Fundam., vol. 15, pp. 59-64, 1976.

[2] J. Gross and G. Sadowski, "Perturbed-chain SAFT: An equation of state based on a perturbation theory for chain molecules", Ind. Eng. Chem. Res., vol. 40, pp. 1244-1260, 2001.

[3] S. S.-S. Huang, A.-D. Leu, H.-J. Ng, and D. B. Robinson, "The phase behavior of two mixtures of methane, carbon dioxide, hydrogen sulfide, and water", Fluid Phase Equilib., vol. 19, pp. 21-32, 1985

[4] W. G. Chapman, G. Jackson, and K. E. Gubbins, "Phase equilibria of associating fluids: chain molecules with multiple bonding sites", Mol. Phys., vol. 65, pp. 1057-1079, 1988.

[5] W. G. Chapman, K. E. Gubbins, G. Jackson, and M. Radosz, "New reference equation of state for associating liquids", Ind. Eng. Chem. Res., vol. 29, pp. 1709-1721, 1990.

[6] J. Gross, "Entwicklung einer zustandsgleichung für einfache, assoziierende und makromolekulare stoffe", Doctoral Dissertation, Technischen Universität Berlin, Berlin, Germany, 2001.

[7] M. L. Michelsen, "The isothermal flash problem. Part II. Phasesplit calculation”, Fluid Phase Equilib., vol. 9, pp. 21-40, 1982.

[8] L. X. Nghiem and Y.-K. Li, "Computation of multiphase equilibrium phenomena with an equation of state", Fluid Phase Equilib., vol. 17, pp. 77-95, 1984.

[9] L. E. Baker, A. C. Pierce, and K. D. Luks, "Gibbs energy analysis of phase equilibria", Soc. Pet. Eng. J., vol. 22, pp. 731-742, 1982.

[10] M. L. Michelsen, "The isothermal flash problem. Part I. stability", Fluid Phase Equilib., vol. 9, pp. 1-19, 1982

[11] R. Fletcher, Practical Methods for Optimization, 2nd ed., New York: Wiley Interscience, 1987.

[12] D. N. Justo-García, F. García-Sánchez, and A. Romero-Martínez, "Isothermal multiphase flash calculations with the PC-SAFT equation of state", Am. Inst. Phys. Conf. Proc., vol. 979, pp. 195-214, 2007.

[13] R. Nutakki, A. Firoozabadi, T. W. Wong, and K, Aziz, "Calculation of multiphase equilibrium for water-hydrocarbon systems at high temperatures", Paper SPE/DOE 17390 presented at the SPE/DOE Enhanced Oil Recovery Symposium, Tulsa, Oklahoma, April 17-20, 1988.

[14] Z. Li and A. Firoozabadi, "Cubic-plus-association equation of state for water-containing mixtures: Is "Cross association" necessary?", AIChE J., vol. 55, pp. 1803-1813, 2009.

[15] G. Schmidt and H. Wenzel, "A modified van der waal's type equation of state", Chem. Eng. Sci., vol. 35, pp. 1503-1512, 1980.

[16] G. M. Kontogeorgis, E. C. Voutsas, I. V. Yakoumis, and D. P. Tassios, "An equation of state for associating fluids", Ind. Eng. Chem. Res., vol. 35, pp. 4310-4318, 1996.

[17] D. Ambrose, "Vapour-liquid critical properties", NPL Report Chem. 107, Teddington: National Physical Laboratory, 1980.

[18] X. Tang and J. Gross, "Modeling the phase equilibria of hydrogen sulfide and carbon dioxide in mixtures with hydrocarbons and water using the PCP-SAFT equation of state, Fluid Phase Equilib., vol. 293, pp. 11-21, 2010.

[19] D.-Y. Peng and D. B. Robinson, "Two and three phase equilibrium calculations for systems containing water", Can. J. Chem. Eng., vol. 54, pp. 595-599, 1976.

[20] H. R. Knapp, R. Döring, L. Oellrich, U. Plöcker, and J. M. Prausnitz, Vapor-Liquid Equilibria for Mixtures of Low Boiling Substances, Vol. VI, Frankfurt: DECHEMA Chemistry Data Series, 1982.
[21] A. Dhima, J.-C. de Hemptinne, and J. Jose, "Solubility of hydrocarbons and $\mathrm{CO}_{2}$ mixtures in water under high pressure", Ind. Eng. Chem. Res., vol. 38, pp. 3144-3161, 1999.

[22] J. A. Nelder and R. A. Mead, "A simplex method for function minimization”, Comput. J., vol. 7, pp. 308-313, 1965.

[23] J. H. Wegstein, "Accelerating convergence for iterative processes", Comm. Assoc. Comp. Mach., vol. 1, pp. 9-13, 1958.

[24] L. A. Webster and A. J. Kidnay, "Vapor-liquid equilibria for the methane-propane-carbon dioxide systems at 230 and $270 \mathrm{~K}$ ", J. Chem. Eng. Data, vol. 46, pp. 759-764, 2001.

[25] J. P. Kohn and F. Kurata, "Heterogeneous phase equilibria of the methane-hidrogen sulfide system", AIChE J., vol. 4, pp. 211$217,1958$.

[26] O. L. Culberson and J. J. McKetta, "Phase equilibria in hidrocarbonwater systems. iii. the solubility of methane in water at pressures to 10,000 PSIA", Pet. Trans. AIME, vol. 192, pp. 223-226, 1951.

[27] J. A. Bierlein and W.B. Kay, "Phase equilibrium properties of system carbon dioxide-hydrogen sulfide", Ind. Eng. Chem., vol. 45, pp. 618-624, 1953.

[28] K. Tödheide and E. U. Franck "Das zweiphasengeibet und die kritische kurven im system kohlendioxid-wasser bis zu drucken von 3500 bar", Z. Phys. Chem., Neue Folge, vol. 37, pp. 387-401, 1963.

[29] P. C. Gillespie and G. M. Wilson, "Vapor-liquid equilibrium data on water-substitute gas components: $\mathrm{N}_{2}-\mathrm{H}_{2} \mathrm{O}, \mathrm{H}_{2}-\mathrm{H}_{2} \mathrm{O}, \mathrm{CO}-\mathrm{H}_{2} \mathrm{O}$, $\mathrm{H}_{2}-\mathrm{CO}-\mathrm{H}_{2} \mathrm{O}$, and $\mathrm{H}_{2} \mathrm{~S}-\mathrm{H}_{2} \mathrm{O}$ ", Research Report RR-41, Gas Processors Association, Tulsa, Oklahoma, 1980.

[30] F. T. Selleck, L. T. Carmichael, and B. H. Sage, "Phase behavior in the hydrogen sulfide-water system”, Ind. Eng. Chem., vol. 44, pp. 2219-2226, 1952.

[31] R. Nutakki, "Phase behavior calculations for systems with hydrocarbons, Water, and $\mathrm{CO}_{2}$ ", Doctoral Dissertation, Stanford University, California, 1991.

[32] J. C. Brady, J. R. Cunningham, and G. M. Wilson, "Waterhydrocarbon liquid-liquid-vapor equilibrium measurements to $530^{\circ} F^{\prime}$, Research Report RR-62, Gas Processors Association, Tulsa, Oklahoma, 1982.

[33] C. Tsonopoulos and G. M. Wilson, "High temperature mutual solubilities of hydrocarbons and water. Part I: benzene, cyclohexane, and n-hexane", AIChE J., vol. 29, pp. 990-999, 1983.

[34] D.-Y. Peng and D. B. Robinson, "Two- and three-phase equilibrium calculations for coal gasification and related processes" in Thermodynamics of Aqueous Systems for Industrial Applications, Chap. 20, pp. 393-414, S. A. Newman, H. E. Barner, M. Kelin, and S. I. Sandler, Eds. ACS Symposium Series, vol. 133, Washington, D.C., 1980.

[35] J.-N. Jaubert and F. Mutelet, "VLE predictions with the pengrobinson equation of state and temperature dependent $k_{i j}$

calculated through a group contribution method", Fluid Phase Equilib., vol. 224, pp. 285-304, 2004.

[36] D. B. Robinson and D.-Y. Peng, "The characterization of the heptanes and heavier fractions for the GPA peng-robinson programs", Research Report RR-28, Gas Processors Association, Tulsa, Oklahoma, 1978.

[37] R. Privat, F. Mutelet, and J.-N. Jaubert, "Addition of the hydrogen sulfide group to the PPR78 model (predictive 1978, peng-robinson eos with temperature dependent $k_{i j}$ calculated through a group contribution method)", Ind. Eng. Chem. Res., vol. 47, pp. 1004110052, 2008

[38] S. Vitu, R. Privat, J.-N. Jaubert, and F. Mutelet, "Predicting the phase equilibria of $\mathrm{CO}_{2}+$ hydrocarbon systems with the PPR78 model (PR EOS and $k_{i j}$ calculated through a group contribution method)", J. Supercrit. Fluids, vol. 45, pp. 1-26, 2008. 